\title{
The 'Future of Employment' on the Shop Floor: Why Production Jobs are Less Susceptible to Computerization than Assumed
}

\author{
Sabine Pfeiffer* \\ Friedrich-Alexander University Erlangen-Nürnberg, Nuremberg Campus of Technology, \\ Fürther Str. 264c, 90429, Nürnberg, Germany
}

Received: 11.04.2018; Accepted: 20.06.2018; Published: 22.11.2018

\begin{abstract}
Context: Germany is seen as one of the major players in developing what is known as "Industry 4.0". Especially in the manufacturing and the automotive sector, the vocational training system is seen as a precondition and consequence alike for the global success of these sectors. Current research though characterizes production work, especially machine-related tasks, as dull routine work and therefore of high probability of computerization.
\end{abstract}

Approach: Based on qualitative research perspectives and sociological results that reveal the importance of experience and implicit capabilities, this study quantifies what is mostly seen as "non-routine" work. To measure these dimensions of living labouring capacity, an index is introduced that is developed from 18 items of one of the biggest German task-based, representative surveys.

Findings: The contribution challenges the widespread prognosis that production workers face high susceptibility. Comparing data on non-routine share in production and of vocational trained workers with those of Frey and Osborne, the findings stress the mostly neglected importance of non-routine work, even in production and especially with vocational trained, machine-related occupations.

Conclusion: The results draw on how much more employees on the shop floor are apt to handle change, complexity, and imponderabilities than often assumed. If their work

*Corresponding author: sabine.pfeiffer@fau.de

ISSN: 2197-8646

http://www.ijrvet.net 
will or will not be susceptible to novel approaches in robotics or algorithms, therefore, is not a question of routine.

Keywords: VET, Vocational Education and Training, Industry 4.0, Routine Task, Living Labouring Capacity, Machine Work, Experience

\section{Introduction}

With the debate on Industry 4.0, the potential automation of human labor is returning with a new and almost forgotten vehemence. The last few years have seen a widespread discourse of Industry 4.0 (Pfeiffer, 2017), inspiring recent studies to predict future job losses on an unprecedented scale; the most influential one being that by Frey und Osborne (2017) who see $47 \%$ of all jobs in the US labor market at risk of computerization. This study 1 predicts that those who work with machines and in the production sector will bear the brunt of these developments. Frey and Osborne estimate that $98 \%$ of such jobs may be susceptible to automation.

In the eyes of most labor market statisticians, production and machine-based work is monotonous, repetitive, and physically challenging; the loss of such jobs is therefore on the whole not seen as problematic in itself. This study will critically discuss recent labor market research on the potential for automation through new technology and then challenge its distinction between routine and non-routine through qualitative research, revealing an unexpected relevance of non-routine work especially in highly automated and digitalized work environments (section two).

As it is nonetheless difficult to argue against the ever more objective-seeming quantitative data on the basis of qualitatively dense empirical studies, section three introduces an index that highlights "living labouring capacity" (in German: Arbeitsvermögen; Pfeiffer, 2014) rather than routine activity. This novel methodological approach uses the presented qualitative results to construct an index that tries to measure the otherwise unmeasurable phenomena of non-routine (e.g. experience, implicit and embodied knowledge). Utilizing 18 indicators from the 2012 BIBB/BAuA2 Employment Survey (Rohrbach-Schmidt \& Hall, 2013), the labor capacity index (LC Index) unveils the extent to which individuals nowadays are confronted with complexity, unpredictability, and change at the workplace. Section four presents some results for machine-related work in production, while section five discusses these findings and possible consequences for the design of work environments in the so-called Industry 4.0.

\footnotetext{
${ }^{1}$ Some of the conceptual and empirical work for this research originated in the context of the research project 'diGAP-Decent Agile Project Work in the digitized World' (ref. no. 02L15A300); jointly funded by the German Federal Ministry for Education and Research (BMBF) and the European Social Fund (ESF).

${ }^{2}$ BIBB stands for "Bundesinstitut für Berufsbildung" (Federal Institute for Vocational Education and Training; see https://www.bibb.de/en/index.php), BAuA for "Bundesanstalt für Arbeitsschutz und Arbeitsmedizin" (Federal Institute for Occupational Safety and Health; see https://www.baua.de/EN/Home/Home_node.html).
} 


\section{The Limits of the Notion of Routine--and Beyond}

Frey and Osborne (2017) derive their conclusions on digital technology's associated effects on the labor market from US labor market data and the views of technical experts. The authors set out from the assumption that there are barely any remaining limits to computerization; those engineering bottlenecks, i.e. tasks that make automation more difficult or delay its implementation, include perception and manipulation tasks, creative intelligence tasks, and social intelligence tasks (cf. Frey/Osborne, 2017, p. 264) ${ }^{3}$

What particularly interests us here is the question of routine. Frey and Osborne (2017) make certain distinctions on the basis of assessments of the effects of technological change. For example, Autor et al. (2003) introduced a classificatory distinction between non-routine (analytic or interactive) tasks and routine (cognitive or manual) tasks, and indicate two effects of computers: substitution effects (routine tasks are automated) and complementarity effects (support is provided for non-routine tasks).

Frey and Osborne (2013) take up in their analysis what has become a standard way of thinking about the effects of technical change on labor markets (Alda, 2013; Antonczyk, Fitzenberger, \& Leuschner, 2008, hereafter "AFL"; Spitz-Oener, 2006; 2007, hereafter "SO"). Initially, Autor, Levy, and Murnane (2003), hereafter "ALM," had-based on US employment data-posed the question of why the increasing use of computers leads to an increase of highly qualified employment. Their study classified work activity into nonroutine tasks (analytical or interactive) and routine tasks (cognitive or manual), showing two effects of computer usage: a substitution effect (routine work is substituted) and a complementarity effect (support of creativity, flexibility, and complex communication, and thus, of non-routine tasks). Ten years later, Frey and Osborne emphasized the significance of technological progress, pointing to automobiles to make their point. ALM had argued that the apparent irreplaceability of a driver shows the limits of automation, but of course, today the driverless car has become a real possibility.

A problem not only for Frey and Osborne but for many others, including for us in our intention to create a new index, lies in the imprecise task descriptions that characterize the US O*NET dataset and the German employment survey 4 Some of these classification decisions defy comprehension, most likely because the surveys on which they are

\footnotetext{
${ }^{3}$ It is often overlooked that 1) this estimate includes not only risks tied to "digitalization" but also to the "offshoring" of jobs and 2) the authors explicitly refuse to offer a prognosis, speaking rather of potential developments over a long, uncertain period of time of one to two decades. Other authors, too, have recently revisited the historically important argument that had been almost forgotten: technological progress may well lead to the elimination of the need for human labor (Brynjolfson \& McAfee, 2014; Collins, 2013; Pistono, 2014; Pupo, 2014). Today, as so often during previous phases of rapid technological change, this argument is either positively associated with the hope that monotonous and physically strenuous work will finally be replaced with creative work (and opportunities for training workers to be more creative), or it is negatively associated with higher unemployment and widespread workforce de-skilling. These two diametrically opposed discourses inevitably pop up together whenever the connections between technology and work are discussed (Zysman \& Newman, 2006).

${ }^{4}$ Autor $\left(2013\right.$, p. 191) generally criticizes the methodological weaknesses of the $\mathrm{O}^{*} \mathrm{NET}$ database. It provides more than 400 different scales, and different studies choose to employ different scales without apparent reason. Autor's assessment of the $\mathrm{O}^{*} \mathrm{NET}$ dataset is correspondingly reserved: "While I have found that task measures distilled from DOT and $\mathrm{O}^{*} \mathrm{NET}$ can serve as powerful proxies for occupational tasks, I am at best only moderately comfortable with these tools because their complexity and opacity places little discipline on how they are applied and interpreted." The IAB/BIBB dataset does attempt to avoid the "pitfalls" of the O*NET.
} 
based are themselves poorly differentiated. It is interesting, for example, that in Frey and Osborne's index, machine setters are considered highly susceptible to automation. Thus, milling and planning machine setters, operators, and tenders, metal and plastic have a 0.98 chance of being replaced by a machine, followed closely by "crushing, grinding, and polishing machine setters, operators, and tenders" with a 0.97 chance. This surprisingly, if not absurdly high probability estimate may result from difficulties caused by combining the tasks of machine setters and machine operators who have very different responsibilities, or from underestimating the importance of substantive differentiation based on the imperatives of production technology. Even a nearly completely self-steering cyber-physical systems (CPS) cannot function without a machine setter, although it might work just fine with fewer operators. The confusion begins with the fact that the work of setters and operators can vary widely, depending on the production technology used, in terms of required skills and experience or of the extent to which the tasks are routine. This kind of problem is confounded by differences in the task descriptions used in different datasets. Thus, the BIBB/BAuA task classifications differ from those used by SO and ALM (Alda, 2013, pp. 24-25) as do the classifications used by AFL and SO. No classification, including the one provided here, can solve the problem that job tasks are too crudely and generally described and thus open up a lot of room for interpretation. For example, one could find virtually limitless reasons, backed up by examples, for classifying organization, planning, and preparation tasks as interactive or as analytical.

Our interest lies primarily on differentiating between "routine" and "non-routine" tasks. All the studies mentioned above take these categories to be central for estimating the technical potential of replacing human labor. Although they all conceptualize "routine" as the most decisive category for assessing the effects of technical change in terms of the extent to which tasks can be automated, they contain only rudimentary attempts to define it. Ultimately, all task-based approaches set out from the hypothesis of routine-based technical change (RBTC) (Fernández-Macías \& Hurley, 2014, p. 37) and almost always equate routine with repetitive, monotonous work. Further elaboration of the concept of routine is rare. Alda (2013, p. 8), however, does remark in a footnote to the discussion of routine in the ALM classification that " $\mathrm{t}]$ he concept of the routine does not refer to people describing or experiencing certain jobs as monotonous, lacking in variety or anything like that, or to people being habituated to something. It is about whether or not technology has progressed so far as to completely take over the task." Indeed, a "good and useful" definition of routine tasks is a "non-trivial" problem (ibid.: 12). By this, ALM mean that "the experience-based knowledge of the employee takes on a higher significance" in non-routine tasks (ibid.: 15). However, although this comment provides a bit more clarity, it does not in our opinion resolve the basic difficulty, because what experience-based knowledge actually is-and in what sense it becomes important on a daily basis for different tasks-cannot be derived solely from the perspective of technical experts and their ideas about the tasks.

Fernández-Macías and Hurley (2014, p. 48) also note that the wide classifications of routine work, made on the basis of O*NET data for the United States, "are not good measures of routine" because they ultimately derive from antiquated notions of 
production work: "Using physical and quality control variables for the routine task index makes sense if we look at traditional production line jobs that involve mostly manual work and basic tasks with machines," they write. "But the routine content of some jobs may be overestimated or underestimated when relying on these two variable categories" (ibid.). In their own analysis, they conclude that "the extent of routine in different jobs...is not the key driver behind polarization-if anything, it is more related to upgrading, in a similar way as the cognitive index" (ibid.: 69). Because this quantitative finding is consistent with a great range of qualitative findings from the sociology of work literature focusing on subjectifying work action and living labor capacity, we now focus on this connection, so allow us to initially introduce both concepts:

- The concept of subjectifying work action (Böhle, 2013) begins with the individual at work, in possession of the full range of human capacities. We need reason and logic to respond correctly under pressure, but we also need intuition, "gut feeling," and emotions. Humans are not completely brain-driven, we also have bodies. Our bodies "know" and feel; they transmit visual and tactile sensations, and through our bodies we grasp contextual relationships that may not be immediately accessible through logic. These abilities often take time to develop, which is why usually only experienced employees possess them. Theoretical knowledge and routine serve to help with standardized processes and repetitive tasks. Subjectifying action and knowledge, however, is quite different, being defined by four central characteristics: a) holistic perception, b) exploration and dialog, c) intuition and "feeling," and d) an empathetic relationship. The concept understands experience neither as basically inferior to theoretical, scientifically grounded knowledge, nor does it see it as a quality to be completely replaced by the latter. Subjectifying work action is of great significance as an autonomous form of action and knowledge both for planning and practical action as well as for creative, innovative processes that form the basis for coping with unforeseen circumstances. However, an understanding of experience in this sense merely as a set of experiences, which have been acquired, is not sufficient. The perspective of having experiences also refers to a given moment and situation and to specific action methods used to tackle specific situations.

- The analytical conception of living labouring capacity (Pfeiffer, 2014) draws on Kluge and Negt (2014), and transforms Marx's dialectical distinction between the use-value (labouring capacity) and the exchange-value (labor power) into an operationalized model that could be and has been successfully used for empirical studies of digital labor. Labouring capacity has three levels of phenomena: subjectifying corporeal working action, material means and objects of work (even in virtual environments), and the socially and physically experienceable face of globalized work organization. Labouring capacity and labor power are two fundamental aspects, each undergoing historically conditioned change and each behaving in a dialectical relationship to each other that can only be separated clearly into quantitative and qualitative components analytically. Humans develop labouring capacity constantly through the course of their life, applying subjectifying action to all environments they encounter and embracing all dimensions of reality in their everyday life 
within and beyond what we today call the work place. Hence, labouring capacity is not only historically specific, but always more than a unique situation, a single task, or a specific job demands to adopt. This fact and the embodied and immanent qualitative nature of labouring capacity makes it a potentially interminable well for creativity, out of the ordinary solutions, and ad hoc improvisation-a truly genuine potential of our species being, not at all reserved for the so-called creative class (Florida, 2012). Labouring capacity could be seen as a human potential that capitalism relies on without understanding it, exploits it without being able to quantify it, and neglects it even when economic logic thrives to unfold it.

Based on these analytical concepts, the author's own workplace investigations (AUTHOR, 2016) have nonetheless shown that, speaking of routine, things are not as simple as Frey and Osborne claim. For example, let us visit a typical automobile assembly line in a German car manufacturing plant-already highly automated, and with a count of one employee for every robot. But the work done by such employees is far from routine. They supervise eight robots, and in a normal work day, intervene in this highly complex process between 20 and 30 times. In order to do so, they not only require a great deal of specialist knowledge (about programming robots, for instance, or welding technologies) but also context-specific knowledge (concerning quality control, for example, and upstream and downstream processes), as well as experiential knowledge (about the causes of previous disturbances, wear and tear, the way materials react to temperature changes, and so on). Workers frequent interventions are sometimes responses to irregularities or disturbances, but mainly serve to ensure that these do not arise in the first place. What we encounter here, then, is a striking contradiction: while in highly complex and heavily digitized production environments, the significance of living labor is quantitatively decreasing, its role in maintaining these complex production processes is becoming ever more important. This fact nonetheless remains invisible to most statistical approaches to the issue.

Contrary to what is implied by Frey and Osborne (2017), experience here would then seem to be an expression of non-routine activity and its importance in complex and heavily automated and digitized working environments (Hirsch-Kreinsen, 2016). This was already shown by studies conducted in the 1980s on the transition from traditional machines to $\mathrm{CNC}^{5}$ tools (Böhle \& Milkau, 1988) and on the management of complex operations in the process industry (Böhle, 1994). These studies indicated the importance of "subjectifying work action," whose central dimensions include holistic perception, an explorative and dialogical approach, intuition and instinct, and an empathetic bearing. While specialist theoretical knowledge and routine-based practices are important in standardized processes and repetitive, unchanging tasks, subjectifying action helps employees to deal with the (yet) unknown. The notion of subjectifying work action thus recalls those aspects of knowledge and action that figures such as Polanyi (1983) and Dreyfus (1992) identified as hidden and informal and-as genuine human capacitiessuperior even to intelligent forms of technology. A range of empirical studies have lent further weight to the notion of subjectifying work action and highlighted its significance

${ }^{5} \mathrm{CNC}=$ Computer-numerical controlled. 
in various work-related tasks, particularly in non-routine situations. From the perspective of qualitative labor research, then, the customary distinction between knowledge work as a non-routine activity and production work as a routine activity does not stand up to close scrutiny.

More recent studies have also demonstrated that the increasing globalization and standardization of production systems, along with their associated technological transformations, have made production work more complex and thereby increased the significance of non-routine activities. The importance of a "high-tech instinct" was indicated by Bauer et al. (2006) in their study on process chemistry-an area marked by particularly high levels of automation and the early introduction of process management IT systems. Other studies have shown that in automobile assembly and serial production processes, employees increasingly have to deal with more rather than less complexity (Levitt, List, \& Syverson, 2012), even when carrying out so-called "simple" work. Such developments have been observed in the very areas in which robotics have long played an important role (Pfeiffer, 2016).

Qualitative studies at the shop floor level and in the production sector have come to very different conclusions than quantitative labor market research did, which tends to make rather far-reaching predictions about automation-induced job losses on the basis of its findings. What qualitative studies bring to light, then-namely the ongoing centrality of living labor, even for value creation-vanishes when we adopt a quantitative perspective. What is crucial here is that the significance of living labor cannot simply be described as a residual element that has somehow retained its relevance. The following study is built on the working assumption that a combination of qualitative diagnoses of human-machine interaction at the micro-level with quantitative labor-market data at the macro-level will yield insights into likely future developments in the organization of work that neither approach could generate in isolation. Our goal is not to offer specific prognoses but rather to improve the methods of studying relevant developments and to build a basis for the continuous and early reporting of qualitative change in firms and jobs using the large-scale data generated by research into employment and occupations. The increasing qualitative significance of living labor in the face of its quantitative reduction is rather an immanent consequence of the contradictions in the dominant modes of production and the current leap in productive forces resulting from digitization.

\section{Measuring Non-Routine}

On the basis of US labor-market data and expert opinion, Frey and Osborne offered prognoses about the extent to which current and future digital technology will lead to workforce reduction and to changes in the labor market as a whole. They were guided by the assumption that technological progress faces no hindrance except for "engineering bottlenecks"-job tasks that are especially difficult to automate-specifically including "perception and manipulation tasks, creative intelligence tasks und social intelligence tasks" (Frey \& Osborne, 2017, p. 262). Their analytical approach is thus "task-based," 
which offers two decisive advantages in the current context. First of all, technological change at the workplace is no longer exclusively tied to what the firm does but is also influenced by employees' personal digital devices and their habits of using them. Second, the division of labor between humans and machines plays out in its most particular and decisive form in the context of specific job tasks, and it is on this level that we actually see the division of labor shifting or reconstituting itself because of changes in the relationship of technology and work.

Quantitative analyses of large job task datasets may lack the nuance and face validity of studies based on qualitative data, including, for example, sociological case studies of specific businesses and anthropological studies of specific job environments. However, quantitative data does allow for assessments of changes in work over time and across economic sectors, so they should be given serious consideration as long as their limitations are handled appropriately. Given the qualitative studies on the significance of non-routine tasks in production work presented in section two are of empirical relevance, is there a way to quantify the share of non-routine tasks and therefore human labor that is not that easy to replace? In the present section, we shall do this on the basis of the 2012 BIBB/BAuA Employment Survey (Rohrbach-Schmidt \& Hall, 2013). This is an occupation-based representative survey that has been repeated at regular intervals since 1979. The survey asks around 20,000 employees in Germany about changes in their work and their occupational roles.

We do not ask which tasks can be labeled as "routine" or "non-routine" tasks following some pre-defined criteria or assumptions. Instead, we search for components of the nonroutine within tasks. Thus, the first step does not involve looking at all activity items but rather at items that best reflect the characteristics associated with experience.

We do not ask for expert opinion about the feasibility of automation, nor do we make inferences about feasibility based on assumptions. Instead, we try to identify components of the non-routine using the subjective assessment of respondents (as far as this is at all possible using items from the BIBB/BAuA Survey) across all activity items.

We assume that the routine/non-routine dichotomy generates very little traction. No activity is purely routine or purely non-routine. Instead, we postulate a routine/nonroutine continuum, or, better yet, an experience continuum, in every activity. This does not preclude large differences in the relevant dimensions and qualities, in the components themselves, or in the relative significance of the non-routine (or experience).

We avoid the tendency to reproduce the common bias (which creeps in despite having virtually no basis in qualitative research) in the classification of manual work and brainwork such that, implicitly or explicitly, work with machines is equated with routine whilst work with knowledge is equated with creativity. Instead, we look first for non-routine components and then, on this basis, we check the extent to which these components are found in different tasks, branches, and qualification levels. Instead of identifying the routine on the basis of typical activity-based categorizations, we put the task-based approach back on its feet and begin with experience. With this experiencebased approach, we hope to generate new insight especially about which tasks are most susceptible to automation.

Above all, using concepts and empirical findings from research on subjectifying work action and labouring capacity, it is our intention to overcome the tendency to equate 
"routine" with simple, repetitive tasks in the sense of an unchanging load of experience. Guided by the conceptual and empirical perspectives noted above, we conceptualize experience not just as something that can be acquired and "had" but rather as an ever-adapting ability to gain more experience. This ability proves useful especially in dealing with unforeseen circumstances, above all when uncertainty about specific work action prevails. It is useful when decisions have to be made under deadline pressure and without planning, and when decisions have to be implemented successfully-defined for example as free of negative economic repercussions-even without sufficient information or in the absence of all necessary skills. As noted in section three, such situations arise even among untrained assembly workers who, in spite of the fact that their main activity is repetitive, anticipate and prevent the causes of disruptions in production. Based on the logic of the classic ALM classification, this activity would be classified as an easily replaceable, routine manual activity. Based on the logic of Frey and Osborne's schema, the same activity would be classified as engineering bottleneck "perception and manipulation" because it may be characterized by a high share of manual labor in a constrained space and possibly also by the necessity of working in uncomfortable bodily positions.

The aim of the now introduced steps is not to predict the probability of automation in light of new technologies, but rather to highlight the limits of such forecasts. The following elaboration of an appropriate index attempts to make human living labor "measurable." Our starting point here is the contemporary qualitative research outlined in section two. The index incorporates both situational and structural challenges for employees resulting from complexity, change, and unpredictability in the workplace (c.f. Pfeiffer \& Suphan, 2015). The labouring capacity index (LC) is comprised of three components and a multiplier, and is generated as follows:

- The sitCOM index component stands for "situation-specific handling of complexity." Here, three items measure the frequency of which employees engage in situation-specific problem-solving and decision-making activities, both alone and in collaboration with others.

- Seven further items make up the sitUP index component and measure "situationspecific unpredictability": A large amount of subjectifying work action is required when under time pressure, when unpredictability is in play or has to be prevented proactively, and when improvisation is necessary due to the lack of sufficient information, knowledge, and/or skills at the right moment and when non-decision can result in bigger problems.

- The strCOM index component, likewise comprised of seven items: When changes in work equipment, work objects, or work organization occurred during the previous two years with repercussions for the immediate work environment, if they are concurrent with an increase of stress. An increase of stress may can indicate an intensification of work as a result and/or in the context of additional demands brought on by change. We interpret an increase of stress as an indicator that acquiring experience has become more difficult. 
- Multiplier "Relevance of Acquiring Experience (rEX)": If a long training period in the firm is necessary for carrying out a task, this can indicate a need for subjectifying action. Indeed, the mastering of work contexts characterized by complexity and unpredictability is more likely to be learned on the job, not through textbooks or instruction manuals. rEX is coded so as to vary between 0 and 1 . It is of central importance for the index because, as a multiplier, it modifies all other values. If $\mathrm{rEX}=0$, the index value is set to zero, indicating zero subjectifying work action. In this case, we do not assume that the task actually requires zero experience but rather that the proportion of experience necessary to carry it out is very low in comparison to other tasks and thus will very unlikely serve as a barrier to automation.

The LC-Index is multidimensional, as one would expect from the conceptual and empirical foundation that underlies it. All indicators show a significant correlation to each other (Spearman Rho significant at .01).

The LC index can be calculated for a total of 17,479 cases. This yields a score of 0 for $16.9 \%$ of the workers surveyed, and a score of under 0.5 for a further $9 \%$. Respondents with a score below the theoretical average would seem to require a very low orby comparison with the comparatively coarse items-unobservable level of labouring capacity. By contrast, high scores were recorded for $48 \%$ of workers, and very high scores for a further $26 \%$. The measurable index scores $(\mathrm{LC}>0)$ are normally distributed. The LC index mean score was $0.56\left(\mathrm{~N}_{\mathrm{LC}}=17,479 ; \mathrm{SD}=0,281\right)$ and exhibited a slight tendency toward higher index scores. Overall, an LC index score of over 0.5 was registered for the occupations of $74 \%$ of all workers surveyed. The majority of employees in Germany had therefore developed informal skills to help them deal with unpredictability, change, and complexity. This high score shows that the contrast usually drawn between routine and non-routine tasks is inadequate.

Although vocational training in Germany shows signs of stagnation (Nicklich \& Fortwengel, 2017), a majority of the German workforce still does have a vocational qualification. Therefore, we now interpret the LC-Index in terms of formal qualification level, differentiating four levels of the highest qualification certificate acquired: cases with no training or academic education, cases with a vocational training certificate, higher non-academic qualification (technicians and master craftsmen), and finally academic degrees. Persons in the sample with no formal qualification show an under average mean LC-Index value of $0.38\left(\mathrm{~N}_{\mathrm{LC}}=1158 ; \mathrm{SD}=0.325\right)$. All others have LC-Index values above the theoretical mean of 0.5 : Persons with a vocational training certificate score an average mean value of $0.54\left(\mathrm{~N}_{\mathrm{LC}}=10,153 ; \mathrm{SD}=0.289\right)$ technicians score highest with a mean of 0.64 $\left(\mathrm{N}_{\mathrm{LC}}=1,477 ; \mathrm{SD}=0.224\right)$, and thus even higher than those with an academic degree who had an average mean value of $0.61\left(\mathrm{~N}_{\mathrm{LC}}=4,686 ; \mathrm{SD}=0.240\right)$.

The LC-Index values among the least qualified shows a very wide distribution with the lowest quartile extending almost to LC-Index $=0$, and the highest quartile reaching over 0.65 . This result can be interpreted as indicating that the group of persons with the lowest level of formal qualification carry out a great variety of tasks with great variation to the extent to which their jobs require them to use experience to overcome complexity. This strongly suggests that the formal qualification structure alone sheds little light on 
the degree to which tasks are dominated by routine. Indeed, the wide distribution affirms qualitative studies which show that "simple" work is, upon closer inspection, often much more complex than it first appears (c.f. Lacher, 2006).

\section{Non-Routine and the Highly Automated Shop-Floor}

Frey and Osborne see machine-based labor as particularly susceptible to automation, in two respects: first, such work largely consists of routine tasks; second, production is seen as the most important area of application for new developments in Industry 4.0 automation and robotics. Table 1 shows to what extent Frey and Osborne (2017, pp. 269-278) see machine-related occupations as susceptible to future technological change. Most of them score with a probability of computerization of $90 \%$ or way beyond that, thus, they are ranked as most-computerizable. The table contrasts these figures with mean LC-values for similar occupations in Germany (ISCO code 08, three digits); the majority showing scores above the theoretical mean between 0.5 and 0.63 . Only machine feeders and production workers without a specific vocational profile score below. The comparison shows that at least in Germany with its traditionally strong vocational system, workers in the field of production often do cope with change, imponderability, and complexity, applying non-routine capabilities much more than assumed by Frey and Osborne.

The industrial branches of automotive and mechanical engineering (and within these, the domains of production and assembly) are key to the implementation of Industry 4.0 and novel approaches of automation and robotics. Of all respondents, first we consider mechanical and automotive engineering $(\mathrm{N}=1.196)$, along with machine-based occupations, i.e., those that the studies discussed above regard as highly routinized and particularly susceptible to automation. We shall turn to the LC index scores generated for occupations that are particularly relevant to Industry 4.0 amongst all industrial branches. Occupations were selected from the areas of mechatronics and of production planning, which both currently represent modernized vocational occupations and mostly include IT related tasks, e.g., programming and monitoring-embedded systems. We here selected occupations according to the German classification of occupations (Klassifikation der Berufe-KldB), which aligns much better with the vocational system in Germany than the ISCO codes. Surprisingly high scores, for example, were recorded for machine and production-based occupations with a higher share of IT-related requirements like "mechatronics and automatization (KldB 242)" with $\emptyset \mathrm{LC}=0.71\left(\mathrm{SD}=0.145 ; \mathrm{N}_{\mathrm{LC}}=34\right)$ or technical production planning and monitoring (KldB 273) with $\emptyset \mathrm{LC}=0.67(\mathrm{SD}=0.228$; $\mathrm{N}_{\mathrm{LC}}=272$ ).

The results clearly show that employees in the automotive and mechanical engineering as well as in other industrial branches-even those engaged in machine and productionbased work-are often confronted with unpredictability, change, and complexity. The idea of dull routine work therefore does not apply here, and the quantitative figures support the qualitative research presented above. The figures further show that technical vocational training seems to provide the appropriate capabilities, and that non-routine work is something to be considered as functional on the shop floor and not only as a characteristic of academic qualification. 
The 'Future of Employment' on the Shop Floor

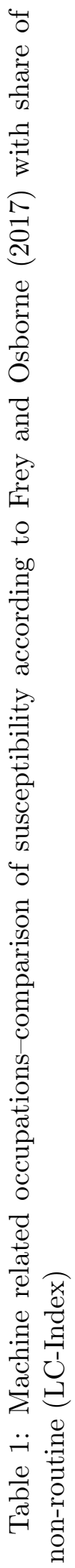

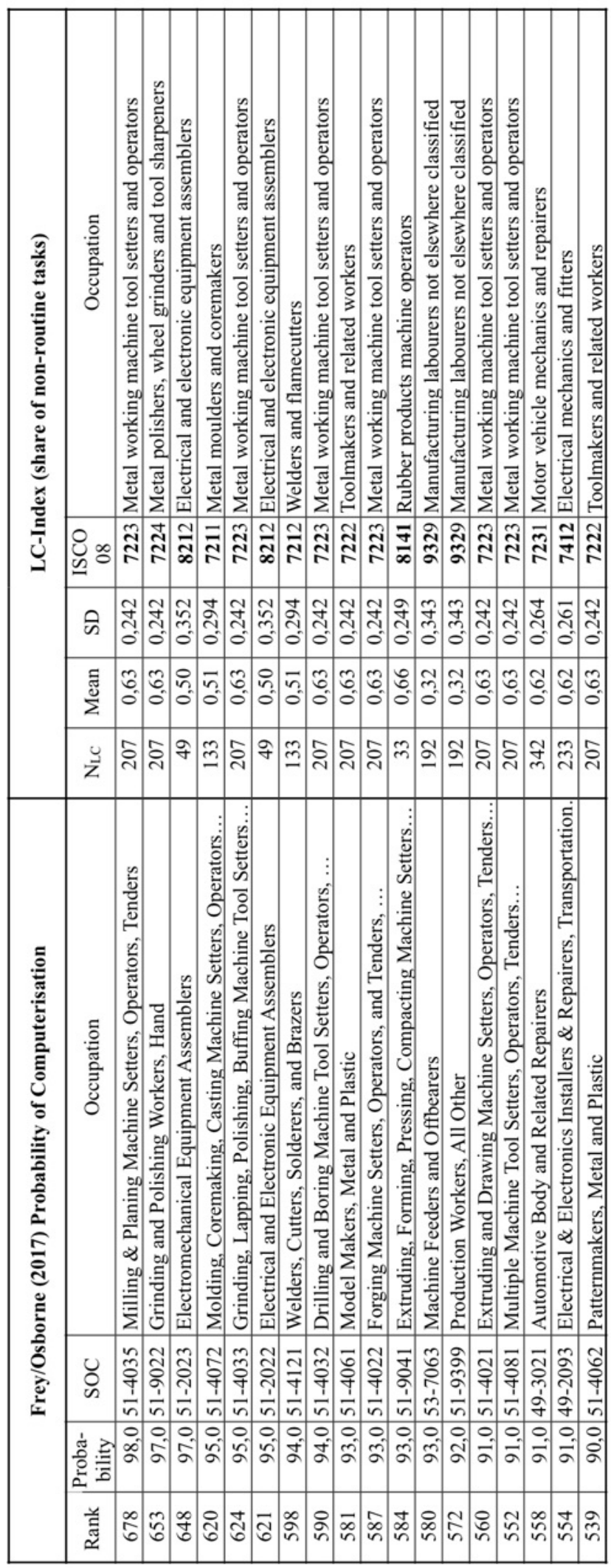




\section{Coping with Automation is more than Routine}

Automation, first of all, aims to replace workers, and those in production, again, are seen as the first to be fired according to recent studies like that by Chui et al. (2015) or by Frey and Osborne. Their conclusions on the replaceability of human labor with robotics, algorithm, and other novel representations of 4.0 automation are based on a notion of routine work that has been neither empirically nor theoretically validated, but contradicts qualitative research in the area, which showed that it is obvious that in highly automated environments, non-routine tasks play a central role. This study tried to quantify that by introducing an index that makes evident what so often is overseen and neglected: phenomena of living human labor. The results point towards the special role of vocational training. Those applying Frey and Osborne's US-based study to Germany (Bonin, 2015) often assume a one-to-one correspondence of the two economies, but the qualification structures of US and German labor markets are actually not very similar. In Germany, the variety of employment categories is greater than anywhere else in the world. As a result (and a necessary condition) of the high complexity of its national economy-indeed, it is one of the most complex economies in the world-an extraordinarily high number of employment categories are involved in the production of most German goods (Hidalgo \& Hausmann, 2009, p. 10573). Even within the EU28, Germany has an exceptional status. It takes, on average, 70 different occupations (ISCO categories) to account for 50 percent of employment in any given sector (NACE categories) of the German economy. In the European Union as a whole, 65 jobs suffice, and in the majority of countries, the value is much lower, ranging between 30 and 50 (Fernández-Macías \& Hurley, 2014, p. 87). Germany may be a special case as its special status is probably best explained by its highly differentiated dual vocational training system; two-thirds of all employees in Germany are still dual-trained (Bosch, 2014). Although non-routine is a global phenomenon, employees with a formal vocational training seem to be adapting highly to requirements at the worksite that come with complexity, change, and imponderabilities. Our results reveal deficits not only in human factors of production, but also in firms and in the established forms of technology development and work organization. If there is anything that cannot be duplicated in an increasingly digitalized world, it is the unique variety of formal qualifications of Germany's workforce. The dual system of vocational apprenticeship and professional development has created a diversely qualified middle class in Germany, in contrast to most countries in the world. Not only does this significantly increase the German economy's capacity for innovation-an assertion supported by our analysis. It also gives rise to the fact that not just a small group of highly qualified employees, but indeed the majority of Germany's employees are capable of dealing with complexity and unpredictability. Experience as a dynamic resource instead of static routine: human labouring capacity, in all its diverse and under-appreciated facets, is a major reason why individuals can learn to deal with complexity and unpredictability. As has already been recognized, it is this ability, which we have tried to measure quantitatively using the LC-Index, that enables us to engage the increasingly significant "ironies of automation": "[t]he more we depend on technology and push it to its limits, the more we need highly-skilled, well-trained, well-practised 
people to make systems resilient, acting as the last line of defense against the failures that will inevitably occur" (Baxter, Rooksby, Wang, \& Khajeh-Hosseini, 2012, p. 65, our own italics).

The central question regarding the link between non-routine work and Industry 4.0 is thus not: Which tasks potentially could be lost to automation tomorrow? The more relevant question is instead: How can the specific potential of living labor be used and recognized for the formation of Industry 4.0 today?

Industry 4.0 technologies will result in deep changes in production, assembly, and maintenance work. This has nothing to do with the introduction of one new technology (such as with the introduction of laser technologies a few years ago). Industry 4.0 bundles a variety of new technologies and application scenarios, all of which vary in terms of the maturity of the technology involved and the systemic effects they set off. In Industry 4.0, future forms of automation will be more disruptive and risky because they introduce a wholly new quality of demands on performance.

Industry 4.0 should be seen as an innovation process for a productive environment in which established procedures for incremental automation along known technological paths and using well-practiced teams are reaching their limits. Industry 4.0 does not involve simply automating already-established manufacturing routines but rather managing and forming the innovation process, which is itself open-ended and to some extent never fully plannable. At the same time, however, new technologies and their advantages have to be integrated into a more and more mass-customized, personalized production robustly and quickly. Even in the early phases, plant availability must not be endangered.

Innovators often lack specific production and process knowledge: Many relevant technologies originate not in established R\&D (research and development) labs of the capital goods industry but in information technology. With applications like big data, there is often a lack of specific knowledge about production technologies and little experience with production processes that involve the handling of materials. Industry 4.0 companies coming from the IT industry often have no sense for the exigencies that arise in the highly synchronized mass production of technologically sophisticated products. The high dynamism and the high variety of technical possibilities are often too much for even top decision makers and management to cope with. In this environment, solutions to problems are implemented that unnecessarily increase complexity and thus put plant availability at risk.

Long- practiced forms of work organization and regulation are approaching their limits: Established processes and institutions of codetermination or of the regulation of worker safety and data security are failing to adapt quickly enough to technological innovation. It is becoming ever more difficult to keep an eye on every relevant issue and intervene in a timely manner. Even already-introduced technologies change through software updates more often and more significantly than in the past, which necessitates new assessments and possibly new rules of data security and worker safety. New procedures have to be developed in order to avoid getting stuck in an exclusively reactive posture.

Skilled employees are needed more than ever and must be able to do more, but the areas in which they work are perceived as unattractive: Industry 4.0 will increase the 
need for more highly qualified and more narrowly specialized warranty operations in many areas of production, assembly, and maintenance. Intelligent processes increase systemic complexity through their sensors and algorithms. Human workers will thus need to apply much more specialized knowledge and experience-based knowledge than ever when disruptions occur, although they will occur less often. Yet, current productionline jobs are still highly constrained by shifts and clocks and are thus not attractive for highly qualified technicians. The demands on those who must create good jobs and recognize good performance are thus also increasing.

Generate sustainable competitive advantages that are not easily copyable: On one hand, the early integration into production of Industry 4.0 technologies is necessary from the perspective of generating competitive advantages, but on the other hand, this strategy is also a source of risk and expense. Technologies that are in a beta-testing phase today will be the standard in a few years. Competitors can catch up by implementing them with less risk and cost. Sustainable competitive advantages can be secured only when specific, not easily copyable applications are developed. The strategically most important interface, and the one that needs to be given the most attention, is the division of labor between human and machine, between human experience and algorithm.

These challenges can be best met by including the 74 percent of the German workforce that already possesses a high amount of experience-based knowledge and is coping with non-routine tasks day-by-day in the early formation of Industry 4.0. To design this formation towards a successful transformation, the needed resource is already available: employees' labouring capacity. However, there is no great participatory tradition for innovation in technology development, which brings up the issue of how it can be introduced. What changes are necessary in our still quite rigid and still very hierarchical corporate organizational structures that would allow employees to utilize their capabilities in self-organizing, agile innovation processes across corporate divisions and across disciplinary lines? How can the experienced-based knowledge of employees be brought into participative processes of technology development? And how, finally, can the new jobs that are created be organized within innovative processes and participatory organizational forms so as to guarantee that innovative work environments arise in which people are able to develop living labouring capacity? This is necessary if, in the future, those workers are to be enabled to deal with complexity and unpredictability, most especially in an Industry 4.0 setting. In other words: How can Industry 4.0 on the factory floor be organized as an innovation process by and with the employees?

\section{References}

Alda, H. (2013). Tätigkeitsschwerpunkte und ihre Auswirkungen auf Erwerbstätige. Bonn: BiBB.

Antonczyk, D., Fitzenberger, B., \& Leuschner, U. (2008). Can a Task-Based Approach Explain the Recent Changes in the German Wage Structure? (Discussion Paper No. 08-132). Mannheim: ZEW Zentrum für Europäische Wirtschaftsforschung. Retrieved from http://www.zew.de/de/publikationen/5244 
Autor, D. H. (2013). The "task approach" to labor markets: an overview. Journal for Labour Market Research, 46, 185-199.

Autor, D. H., Levy, F., \& Murnane, R. J. (2003). The skill content of recent technological change: An empirical exploration. The Quarterly Journal of Economics, 118(4), 1279-1333.

Bauer, H. G., Böhle, F., Munz, C., Pfeiffer, S., \& Woicke, P. (2006). Hightech-Gespür: Erfahrungsgeleitetes Arbeiten und Lernen in hoch technisierten Arbeitsbereichen. Ergebnisse eines Modellversuchs beruflicher Bildung in der chemischen Industrie. Bielefeld: Bertelsmann.

Baxter, G., Rooksby, J., Wang, Y., \& Khajeh-Hosseini, A. (2012). The ironies of automation ... still going strong at 30? In Proceedings of the 30th European Conference on Cognitive Ergonomics (pp. 65-71). Edinburgh.

Böhle, F. (1994). Relevance of experience-based work in modern processes. AI \& Society. Journal of Human Centered Systems and Machine Intelligence, 8(3), 207-215.

Böhle, F. (2013). 'Subjectifying Action' as a Specific Mode of Working with Customers. In W. Dunkel \& F. Kleemann (Eds.), Customers at Work - New Perspectives on Interactive Service Work (pp. 149-174). Basingstoke York: Palgrave Macmillan.

Böhle, F., \& Milkau, B. (1988). Computerised Manufacturing and Empirical Knowledge. AI \& Society, 2, 235-243.

Bonin, H. (2015). Übertragung der Studie von Frey/Osborne (2013) auf Deutschland (Kurzexpertise No. 57). Berlin: Bundesministerium für Arbeit und Soziales.

Bosch, G. (2014). Facharbeit, Berufe und berufliche Arbeitsmärkte. WSI-Mitteilungen, $67(1), 5-13$.

Brynjolfson, E., \& McAfee, A. (2014). The Second Machine Age: Work, Progress, and Prosperity in a Time of Brilliant Technologies. New York, London: Norton.

Chui, M., Manyika, J., \& Miremadi, M. (2015). Four fundamentals of workplace automation. McKinsey Quarterly, (November). Retrieved from http://www.mckinsey.com/ insights/business_technology/four_fundamentals_of_workplace_automation

Collins, R. (2013). The end of middle class work: No more escapes. In I. Wallerstein, R. Collins, G. Derlugian, \& C. Calhoun (Eds.), Does Capitalism Have a Future? (pp. 37-70). Oxford, New York: Oxford University Press.

Dreyfus, H. L. (1992). What Computers Still Can't Do. Cambridge: MIT Press.

Fernández-Macías, E., \& Hurley, J. (2014). Drivers of recent job polarisation and upgrading in Europe: Eurofound Jobs Monitor 2014. Luxembourg: Eurofound. Retrieved from http://eurofound.europa.eu/sites/default/files/ef_files/pubdocs/2014/19/en/1 /EF1419EN.pdf

Florida, R. (2012). The Rise of the Creative Class Revisited. Philadelphia: Basic.

Frey, C. B., \& Osborne, M. A. (2017). The future of employment: How susceptible are jobs to computerisation? Technological Forecasting and Social Change, 114, 254-280. https://doi.org/dx.doi.org/10.1016/j.techfore.2016.08.019

Hidalgo, C. A., \& Hausmann, R. (2009). The building blocks of economic complexity. PNAS - Proceedings of the National Academy of Sciences of the United States of America, 106(26), 10570-10575. https://doi.org/10.1073/pnas.0900943106

Kluge, A., \& Negt, O. (2014). Elements of a Political Economy of Labor Power. October, 149(Summer), 9-34. 
Lacher, M. (2006). Ganzheitliche Produktionssysteme, Kompetenzerwerb und berufliche Bildung. In U. Clement \& M. Lacher (Eds.), Produktionssysteme und Kompetenzerwerb. Zu den Veränderungen moderner Arbeitsorganisation und ihren Auswirkungen auf die berufliche Bildung (pp. 73-92). Stuttgart: Franz Steiner.

Levitt, S. D., List, J. A., \& Syverson, C. (2012). Toward an Understanding of Learning by Doing: Evidence from an Automobile Assembly Plant (NBER Working Paper). Cambridge: National Bureau of Economic Research.

Nicklich, M., \& Fortwengel, J. (2017). Explaining the puzzling stagnation of apprenticeships in Germany's security services: A case of insufficient institutional work? Journal of Professions and Organization, 2017(0), 1-22. https://doi.org/10.1093/jpo/ jox008

Pfeiffer, S. (2014). Digital Labour and the Use-value of Human Work. On the Importance of Labouring Capacity for understanding Digital Capitalism. TripleC. Journal for a Global Sustainable Information Society, 12(2), 599-619. Retrieved from http://www.triple-c.at/index.php/tripleC/article/view/545/610

Pfeiffer, S. (2016). Robots, Industry 4.0 and Humans, or Why Assembly Work Is More than Routine Work. Societies, 6 (Special Issue Robots and the Work Environment)(2), 16. https://doi.org/10.3390/soc6020016

Pfeiffer, S. (2017). The Vision of 'Industrie 4.0' in the Making -a Case of Future Told, Tamed, and Traded. Nanoethics, 11(1), 107-121. https://doi.org/10.1007/s11569016-0280-3

Pfeiffer, S., \& Suphan, A. (2015). The Labouring Capacity Index: Living Labouring Capacity and Experience as Resources on the Road to Industry 4.0 (Working Paper No. Working Paper 20152 (draft v1.0 2nd August 2015)). Stuttgart: University of Hohenheim, Chair of Sociology. Retrieved from http://www.sabinepfeiffer.de/files/downloads/2015-Pfeiffer-Suphan-EN.pdf

Pistono, F. (2014). Robots Will Steal Your Job But That's Ok. How To Survive the Economic Collapse and be Happy. Los Angeles: Federico Pistono.

Polanyi, M. (1983). The Tacit Dimension. Gloucester: Peter Smith.

Pupo, A. (2014). Cognitivity Everywhere: The Omnipresence of Intelligent Machines and the Possible Social Impacts. World Future Review, 6(2), 114-119. https://doi.org $/ 10.1177 / 1946756714533206$

Rohrbach-Schmidt, D., \& Hall, A. (2013). BIBB/BAuA Employment Survey 2012. (BIBB- FDZ Data and Methodological Reports No. 1/2013). Bonn: BIBB. Retrieved from doi:10.7803/501.12.1.1.30

Spitz-Oener, A. (2006). Rising Educational Demands: Looking outside the Wage Structure. Journal of Labor Economics, 24(2), 235-270. Retrieved from http://www.jstor. org $/$ discover $/ 10.1086 / 499972$ ?uid $=3737864 \& u i d=2 \& u i d=4 \& \operatorname{sid}=21104103830601$

Spitz-Oener, A. (2007). The Returns to Pencil Use Revisited (Vol. 2729). Bonn: IZA (Forschungsinstitut zur Zukunft der Arbeit). Retrieved from http://ftp.iza.org/dp27 29.pdf

Zysman, J., \& Newman, A. (Eds.). (2006). How Revolutionary was the Digital Revolution? National responses, market transitions, and global economy. Stanford: Stanford University Press. 


\section{Biographical Note}

Dr Sabine Pfeiffer is professor for Sociology (technology, labor and society) at Nuremberg Campus of Technology, Friedrich-Alexander University Erlangen-Nürnberg, Germany. Her research interests focus on Industry 4.0, digital labor, work experience, and automatization. 